\title{
A Study on Color Design of OTC Drug Packaging for Common Elderly People Based on CIELab Color Mean Method
}

\author{
Jie Du \\ Xi'an University of Technology \\ Xi'an, China
}

\author{
Yujia Gao \\ Xi'an University of Technology \\ Xi'an, China
}

\begin{abstract}
Purpose: This paper analyzes and studies the overpack color of all over-the-counter aged audience drugs in the market, and points out that the characteristics of drug packaging in this special population can satisfy the consumption psychology of the crowd by combining the color characteristics of disease and curative effect. Method: The color of over-the-counter drug outer packaging for the elderly was extracted, and the color scatter plot of the sample drug outer packaging was obtained by using the Photoshop color mean method based on CIELab, and the color data of the sample were sorted and analyzed. To further study the color law of the effect of curative color and pathological color in the design of medicine outer packaging for the aged, through the design correlation between the visual principle of color and the pharmacological property of medicine, the design importance of humanistic care for the aged audience is reflected more deeply. Result According to the concept of disease color and curative color, the law of drug outer packaging color design is obtained, which is more suitable for the aged audience, and provides a better color design idea for drug outer packaging design. Conclusion Through the combination of disease color and curative color, the information of medicine can be conveyed more quickly and accurately in color design, and the aged audience can establish effective visual communication, so as to reflect the emotional resonance of caring and caring for the crowd.
\end{abstract}

Keywords-aging audience drug; outer packaging color; disease color; curative effect color

\section{INTRODUCTION}

On September 23, 2014, the National working Committee on Aging issued the first Blue Book on the Development of Aging Industry in China. The report points out: in 2013, the number of the elderly population in China has reached 202 million, and the aging level of the population has reached 14.90. China is now in the early stage of an aging society [1]. China's population is now aging, its drug consumption accounts for more than half of the total drug consumption. The emphasis on the aged people should not only be reflected in the improvement of the quality of medicine, but also in the color design of drug packaging.

At present, the packaging of common diseased drugs among the aged in the market, whether from the color, marking, and other aspects of the outer packaging, is more focused on carrying the information function of the drugs, but lacks the design thought of "design for the aged audience" and "how to design for the aged audience". In this situation, the drug packaging design is particularly important for the specific psychology of this group. Non prescription drugs (OTC refers to drugs that consumers can directly purchase and use without prescription) has a high degree of freedom of choice, which leads to a closer relationship between drugs and patients. [2] Therefore, in the color design of drug packaging for the aged audience, we should give full play to the psychological role of color language, reasonable choice and use of appropriate and effective color, which can form a more appropriate two-way communication with consumers' psychology.

\section{RESEARCH CONTENT}

Color is one of the most easily influential elements in visual communication, which can evoke association and communicate with people at the psychological level [3].From the visual point of view, color is a special emotional language, with symbolic and associative significance, different colors will make the audience produce different emotional feedback. When the vision touches a certain color, the brain nerve receives signals from the color and associates them. In the design of drug packaging, colors play a special role in the psychological efficacy of consumers. Different colors usually represent different effects of drugs, which are characterized by large color contrast and concise patterns.

This is used to achieve psychotherapy and reflect the color of the disease is therapeutic color. "Curative Color" refers to the color that the audience associates with according to the efficacy of drug treatment [2]. For example, reduce blood pressure, sedative kind medicine is blue commonly, green pack Gynaecology medicine is purple, pink, red and so on mostly; health care class, tonic medicine is commonly red; assist digestion kind is green, yellow commonly and so on. Color psychology is the subjective reaction of people to the objective world [4]. Diseased color is an associative color produced by the audience according to the feeling of a disease [2]. If the patient is inflamed by swelling and pain, the feeling of the condition is associated with red, red is the symptoms of swelling and pain inflammation color. Symptom color can directly communicate with patients through psychological level, and assist patients to choose medicine according to psychological color. 
The color of disease and the color of curative effect depend on each other, but the color of disease is more subjective than the color of curative effect. When the efficacy of a drug color is unclear, the color of the disease can be used in the design of the drug packaging, vice versa." symptom color" and "curative color" refer to the psychological feeling of the patient when the color corresponds to the illness and the psychological feeling after the cure. It is the manifestation of the color design strategy and the psychological induction used in the medicine outer packaging. The design process of drug outer packaging starts from the process of patients' illness, puts themselves in the group of people's psychological feelings, and then designs and makes a reasonable drug outer packaging, see "Fig. 1".

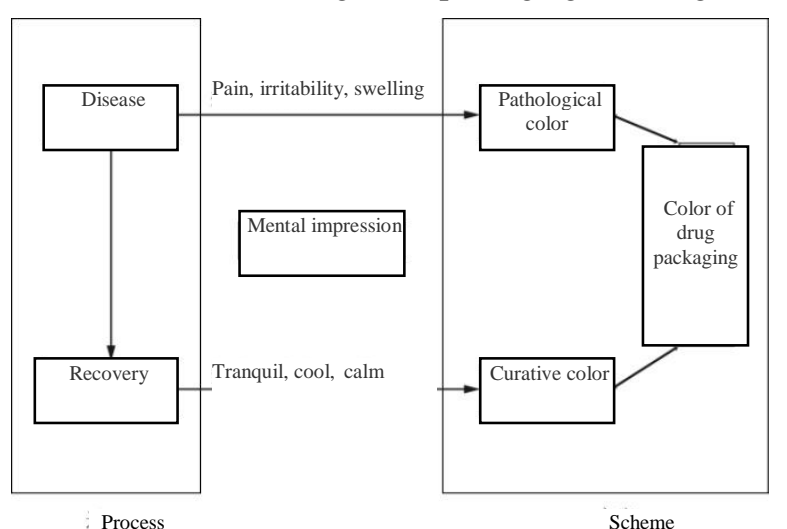

Fig. 1. Design process of drug outer packaging.

\section{RESEARCH TECHNIQUE}

The Photoshop color mean value method based on CIELab is studied. CIELab color system is the color space recommended by ICC (International Color Consortium). The color space can better reflect people's psychological feelings about the object color [5]. In the expression of color, the most complete range is Lab mode, and can make up for the shortcomings of RGB mode and CMYK mode of narrow color range. That is to say, Lab mode can define the most color and is not affected by objective environment.

Lab mode consists of three channels, $a-b, \mathrm{~L}-\mathrm{a}, \mathrm{L}-\mathrm{b}$ (or L-C, $\mathrm{L}-\mathrm{H})$ forming a three-dimensional color space. The first channel "L" means lightness, a channel represents the color range from red to dark green, $\mathrm{b}$ channel represents a range of colors from blue to yellow, $\mathrm{C}$ indicates saturation, $\mathrm{H}$ indicates hue angle value as in "Fig. 2".

$$
\begin{aligned}
& \text { OH: } 0 \text { degree } \supset \text { L: } 0 \\
& \text { Os: } 0 \text { Oa: } 0 \\
& \text { OB: } 0 \text { \% } \% \text { b: } 0
\end{aligned}
$$

Fig. 2. a-b, L-a, L-b (or L-C, L-H) channel.

The color mean method is the result of color mixing of three dimensional color space of all visual elements in the map. This study is limited to the color design of OTC drug outer packaging for the aged audience. In this paper, we select the old OTC medicine packaging map as the sample as in "Table I".Firstly, the data of each color is collected by Photoshop, and the geometric statistics is carried out. Then, the average color of the sample is obtained by means of the average item algorithm. Finally, the color scatter plot is made by the numerical values, and the obtained values are analyzed by the icons.

TABLE I. PART OF THE MARKET COMMON OTC SAMPLES OF ELDERLY DRUGS

\begin{tabular}{|l|l|c|}
\hline \multicolumn{1}{|c|}{ Main Treatment Disease } & \multicolumn{1}{|c|}{ Drug Name } & Sample Size \\
\hline High blood pressure & Torasemide Tablets & 11 \\
\hline Diabetes mellitus & Glibenclamide tablets & 9 \\
\hline Cerebral thrombosis & $\begin{array}{l}\text { Cerebral thrombus } \\
\text { tablet }\end{array}$ & 10 \\
\hline
\end{tabular}

\section{A. Sample Scatter Distribution Diagram}

1) Sample 1: Distribution of color scattered points in the outer packaging of hypertensive drugs, as "Fig. 3", "Fig. 4" and "Fig. 5"

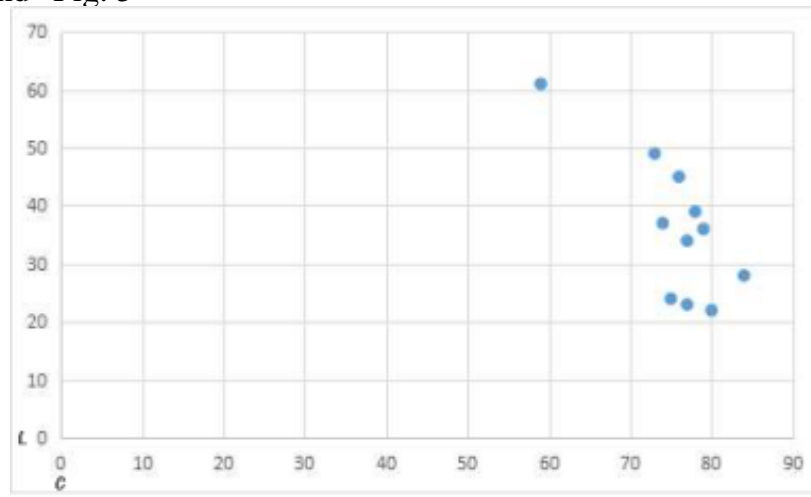

Fig. 3. Distribution of color scattered points in the outer packaging of hypertensive drugs. (L-C)

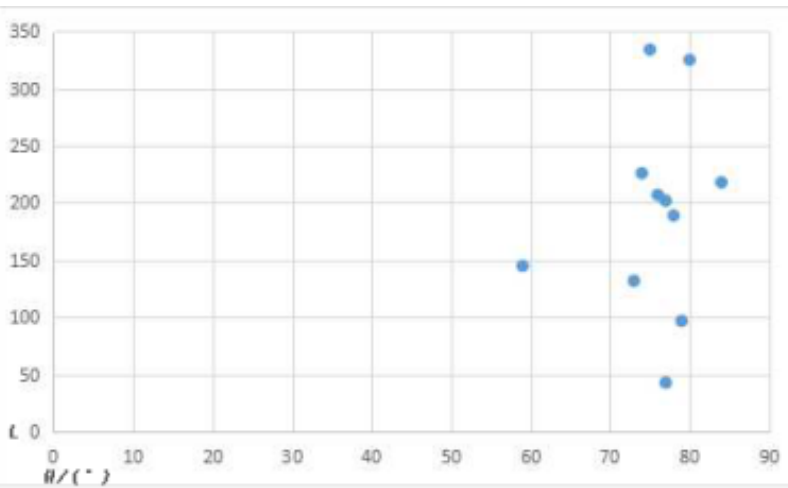

Fig. 4. Distribution of color scattered points in the outer packaging of hypertensive drugs. (L-H) 


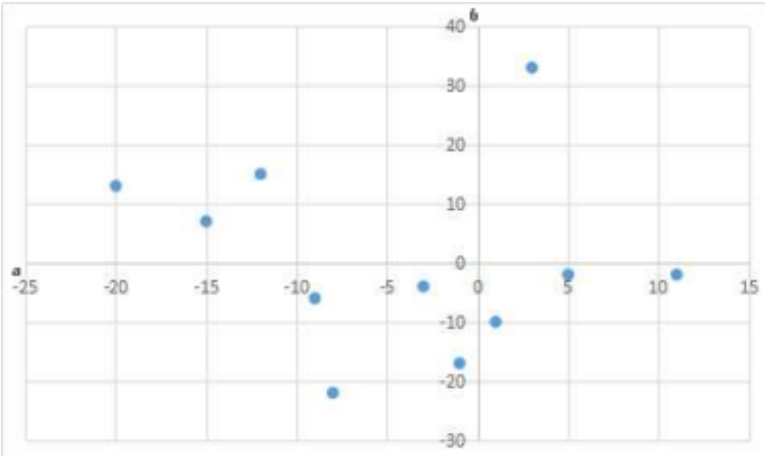

Fig. 5. Distribution of color scattered points in the outer packaging of hypertensive drugs. (a-b)

- From the L-H diagram, of the 11 samples, the L values of the 10 samples are between $20 \sim 50$, indicating that the over-pack color of hypertension drugs in the elderly is low.

- From a-b and L-H diagrams, of the 11 samples, 9 of the samples (about $82 \%$ of the total sample) have a $\mathrm{H}$ value of 70 degrees $\sim 80$ degrees, according to the analysis of the corresponding mean value diagram, most of the samples are distributed in the purple and red color range, indicating that the packaging of hypertension drugs is mostly warm color.

- $\quad$ The $C$ value of 10 samples (about $90 \%$ of all samples) is between 70 and 90, so the saturation is higher.

- $\quad$ Rising blood pressure will bring the patient dizziness, nausea and discomfort symptoms, so its disease color is red, yellow and other warm color.

- The curative effect of hypertension is the coloring that is opposite to the disease. It provides calm and feeling for the patient.

2) Sample 2: Distribution of color distribution in diabetic sulfonylurea packaging, as in "Fig. 6", "Fig. 7" and "Fig. 8".

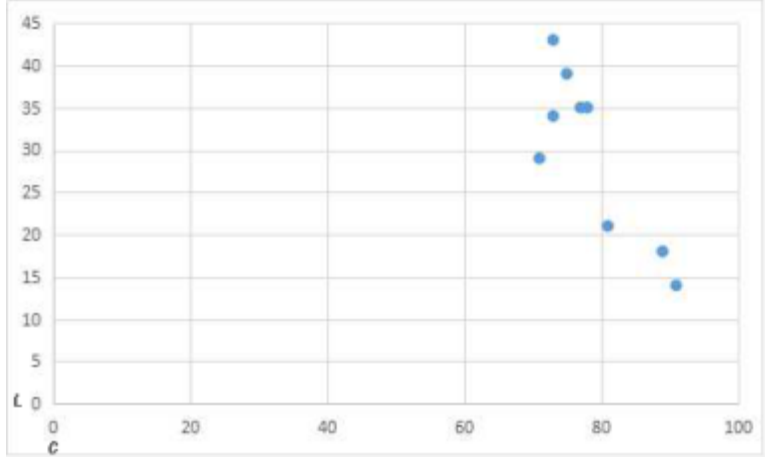

Fig. 6. Distribution of color scattered points in the outer packaging of diabetic sulfonylurea drugs. (L-C)

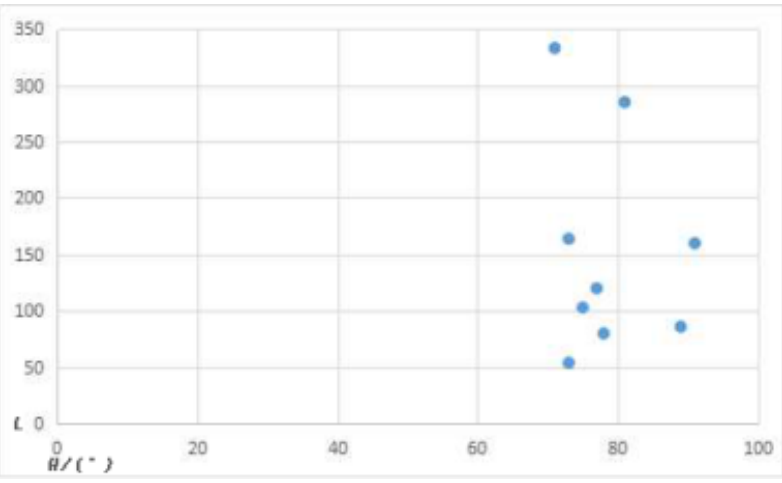

Fig. 7. Distribution of color scattered points in the outer packaging of diabetic sulfonylurea drugs. (L-H)

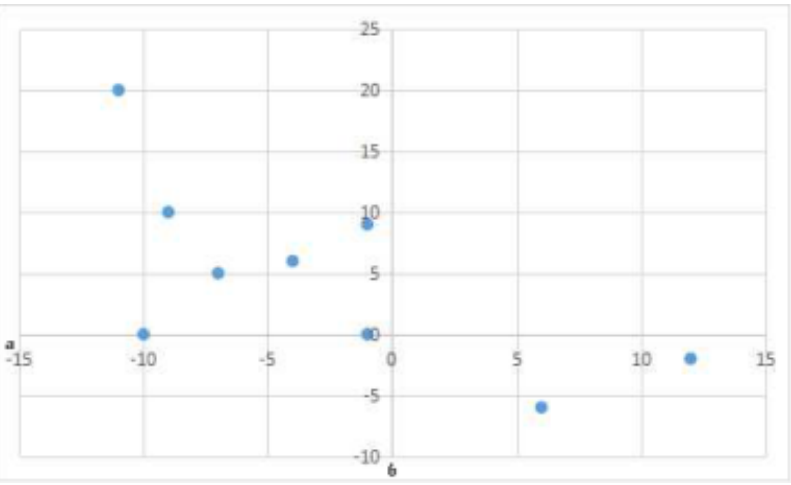

Fig. 8. Distribution of color scattered points in the outer packaging of diabetic sulfonylurea drugs. (a-b)

- $\quad$ L-H diagram showed that in 9 samples, the $\mathrm{L}$ value of all samples is between 30 and 45 , which indicate that the color of the outer packaging of diabetic sulfonylurea drugs in the elderly is low.

- Seen from A-B and L-H diagrams, the $\mathrm{H}$ values of 7 samples (about $78 \%$ of all the samples) are concentrated at $60^{\circ} \sim 80^{\circ}$, distributed in the green and cyan color range, combined with the analysis of the corresponding mean value map, it is shown that the drug of diabetes have a cool color attribute.

- Seen from the L-C diagram, the C value of 7 out of 9 samples (about $78 \%$ of all samples) is in the range of $60 \sim 100$, so its saturation is relatively high as a whole.

- Diabetes mellitus is a group of metabolic diseases characterized by hyperglycemia, the color of the disease should be warm.

- Its curative effect is coloring, which makes people feel calm and cool.

3) Sample 3: Distribution of color scattered points in the outer packaging of cerebral thrombus drugs, as in "Fig. 9", "Fig. 10" and "Fig. 11". 


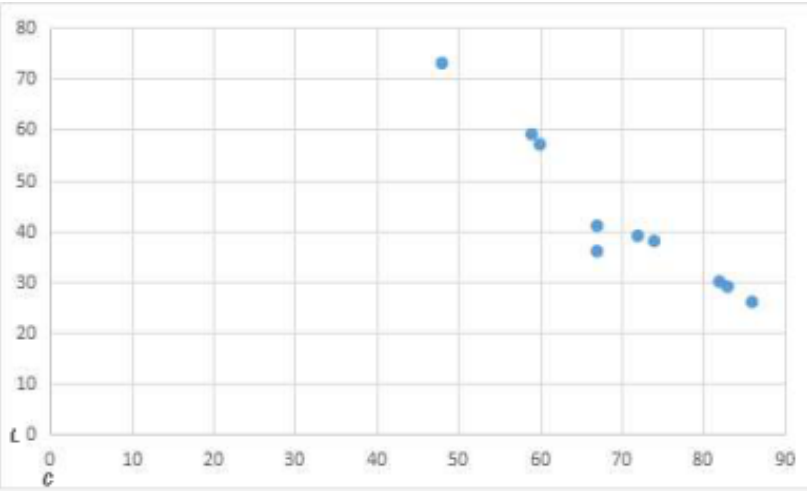

Fig. 9. Distribution of color scattered points in the outer packaging of diabetic sulfonylurea drugs. (L-C)

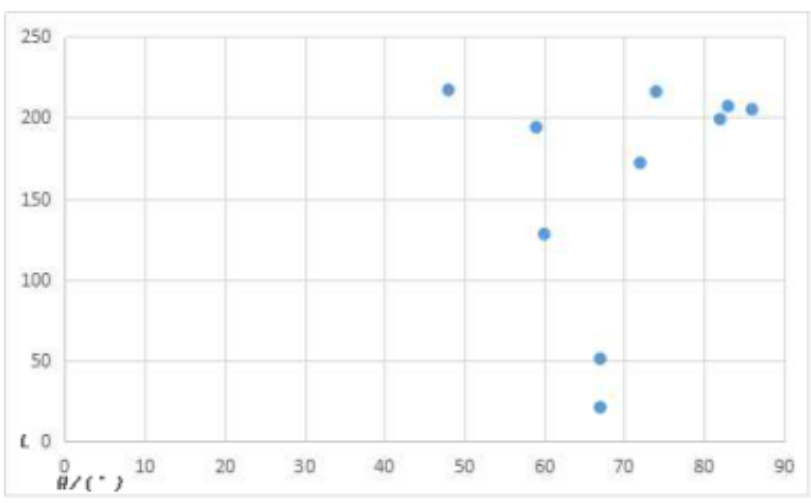

Fig. 10. Distribution of color scattered points in the outer packaging of diabetic sulfonylurea drugs. (L-H)

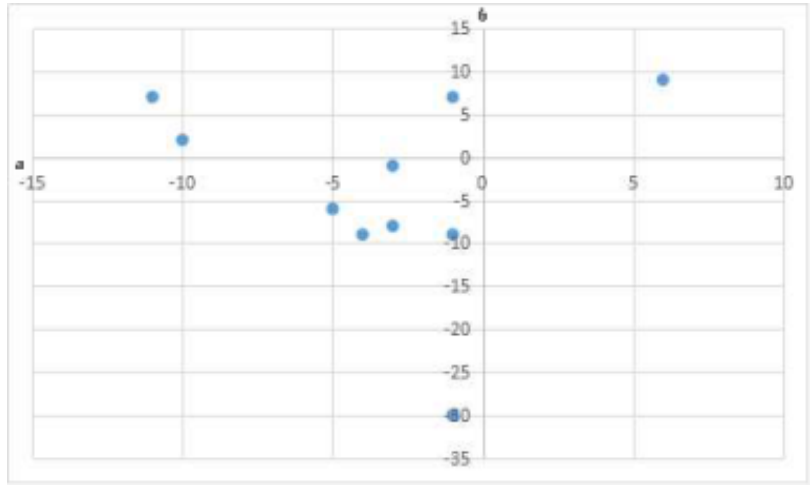

Fig. 11. Distribution of color scattered points in the outer packaging of diabetic sulfonylurea drugs. (a-b)

- $\quad$ From the L-H diagram, we can see that the L value of 7 samples (70\% of all samples) is between 20 50 in 10 samples, the $\mathrm{L}$ value of 3 samples $(30 \%$ of all samples) is between $50 \sim 80$, It shows that the color of external packaging of cerebral thrombosis drugs is mostly low in lightness and high in individual lightness.

- It can be seen from a-b and L-H diagrams that the $\mathrm{H}$ value of 8 samples (about $80 \%$ of all samples) is in the range of $60^{\circ} \sim 90^{\circ}$ in 10 samples, which shows that most of the samples are distributed in the blue color range, indicating that the outer packaging of cerebral thrombus drugs is cool.

- From the L-C diagram, the $\mathrm{C}$ values of 8 samples (about $80 \%$ of the total samples) are concentrated in 60-90 in 10 samples, which indicates the overall saturation of the encephalic thrombosis drug packaging is high.

- Cerebral thrombosis will give patients with symptoms of dizziness and discomfort, so its disease color is red, yellow and other warm color;

- The effective color of hypertension is the opposite of the color of the disease, which can better soothe the patient's nerves.

\section{B. Analysis and Discussion}

Lightness refers to the degree of brightness. [6] The brightness (L) of the selected samples were all low, which indicated that most of the color design of drug outer packaging for the elderly was low, which indicated that the color design of OTC drug outer packaging for the aged audience was of low brightness distribution. Combining with the original packaging of drugs, we can see that the drug outer packaging design for the aged audience takes into account the deep, elegant and plain packaging design of its people, so it generally uses light gray and light brown as the background color, and a few with low transparency decorative shading, or strong black and white contrast, these are the decisive factors affecting the overall brightness. At the same time, the color design of low brightness can comfort the aged audience psychologically and alleviate the negative emotion caused by illness. Hue refers to the appearance of color [6], which is the main feature of color and the root of the inevitable difference of color. Cold and warm (color temperature) refers to the heat produced by color, including physical and psychological aspects [7]. The distribution of $\mathrm{H}$, a and $\mathrm{b}$ values of drug samples varied, and the reasons are complicated. Saturation refers to the purity of color [8]. The saturation (C) of the color mean value map of all samples was high, and the color collocation was obvious in the drug outer packaging, which could guide the vision through the color contrast and highlight the properties and information of the drug.

Hypertension, diabetes mellitus and cerebral thrombosis are common chronic diseases in the elderly, and the corresponding drugs are accompanied by the patients. Tora Semie tablet is a common over-the-counter drug for hypertension, which is effective for edema and hypertension caused by congestive heart failure. Through the analysis of the samples, most of the Tora sameflakes sold on the market show warm color attributes, and the hue range is between purplish red and red. This is consistent with the associative color of the patient based on the feeling of the disease. Therefore, Tora Semie tablets skillfully use the symptoms of the color, showing the characteristics of hypertension. Diabetic sulfonylurea is an over-the-counter drug used in diabetes, mainly by stimulating insulin secretion to play a hypoglycemic effect. Its drug packaging color mainly uses green, cyan and other cool colors. Cold color has a distinct sense of contraction, and it is also the associative color produced by the main 
therapeutic effect of diabetic root medicine, which makes the effective color blend into the color design of drug packaging. Cerebral thrombosis tablet is a widely used non prescription drug for cerebral thrombosis. It has the function of activating blood circulation to dissipate blood stasis, restoring consciousness and dredging collaterals. Most of the samples of cerebral thrombus are in blue color range, indicating that the outer packaging of cerebral thrombus drug is cool. This is because cool colors such as blue can produce cool and refreshing, ice-cool, calming visual effects through vision. The drug packaging color design is combined with the therapeutic color, and the directivity of drug function is expressed accurately and quickly. The overall analysis of drug samples is shown in "Fig. 7".

TABLE II. SAMPLE ANALYSIS CONCLUSION DIAGRAM

\begin{tabular}{|l|l|l|l|}
\hline $\begin{array}{l}\text { Main Treatment } \\
\text { Disease }\end{array}$ & \multicolumn{1}{|c|}{ Drug Name } & \multicolumn{1}{c|}{ Hue } & $\begin{array}{l}\text { Color Design } \\
\text { Strategy }\end{array}$ \\
\hline $\begin{array}{l}\text { High blood } \\
\text { pressure }\end{array}$ & $\begin{array}{l}\text { Torasemide } \\
\text { Tablets }\end{array}$ & $\begin{array}{l}\text { Warm } \\
\text { colour }\end{array}$ & $\begin{array}{l}\text { Pathological } \\
\text { color }\end{array}$ \\
\hline Diabetes mellitus & $\begin{array}{l}\text { Glibenclamide } \\
\text { tablets }\end{array}$ & Cool color & $\begin{array}{l}\text { Therapeutic } \\
\text { color }\end{array}$ \\
\hline $\begin{array}{l}\text { Cerebral } \\
\text { thrombosis }\end{array}$ & $\begin{array}{l}\text { Cerebral thrombus } \\
\text { tablets }\end{array}$ & Cool color & $\begin{array}{l}\text { Therapeutic } \\
\text { color }\end{array}$ \\
\hline
\end{tabular}

Through research and analysis, it was found that the color design of outer packaging of aged audience OTC drugs had a small difference in color design and saturation, but there was a big difference in color. It can be seen that the color relationship between the hue of drug outer packaging and its main treatment function is affected by curative color and pathological color. The therapeutic color and the diseased color are interdependent, influential and related. When the therapeutic color of the drug is easily distorted, the disease color can be used to design the drug outer packaging; for example, the diseased color is not prominent in the design, which can use curative effect color to achieve certain visual psychology treatment. Although therapeutic color and diseased color play a great role in the color design of drug outer packaging and can be replaced by each other, color design should be considered from many angles, such as warm color for cerebral thrombosis, but if red is used directly, the patients are visually stimulated and psychologically affected, which lead to dizziness and nausea in the aged audience. If the cool color design of outer packaging is used, it can play a role in appeasing the audience nerve.

To sum up, the color design of drug outer packaging should be combined with diseased color and curative color, and the contrast of color should be increased, but in the design, we should also grasp the scale. The excellent color design case can realize the good communication between the aged audience and the medicine, and can reflect the scientific nature, rationality and humanistic concern to the audience of OTC drug packaging.

\section{CONCLUSION}

As Najib, one of the founders of Bauhaus, said: "Design is about people, not products." In the design of OTC drug outer packaging for the aged audience, the complex graphic design and color typesetting should be reduced, the contrast should be emphasized, the brightness should be improved, and the design rule of drug color should be fitted more closely. Then combine the two kinds of associative colors, skillfully use the visual psychological influence of color, at the same time, pay attention to the emotional appeal of color expression, give full play to the use of color elements in drug outer packaging, so that it can accurately express the performance of drugs at the same time, to establish effective visual communication with the crowd, and at the same time to play a certain psychological assistance. So that the aged audience to a certain degree of psychological relaxation, pay attention to their psychological demands.

\section{REFERENCES}

[1] "Report on the Development of China's Aging Industry", 2014.9.23

[2] Fu Yu. Research on Color Design of Drug Packaging based on CLELa [J]. Packaging engineering, 2015.3

[3] Kremchuk rose Marianne, Kolasovich A. Sandra. Packaging Design: brand Moulding: from Conceptual Conception to Shelf display [M] Shanghai: Shanghai people's Art Publishing House, 2008

[4] Han Hongyou. Application Research of sensory emotion expression of Packaging Color [J]. Packaging engineering, 2012 (6) : 140-143

[5] Yu Mingwei, Fang Enyin. Study on brightness uniformity of CIELAB and CIECAM02 [J]. Packaging engineering,2010, 31(3): 96-100.

[6] Stewart M.Launching the Imagination: A ComprehensiveGuide to Basic Design[M].New York: Mc Graw Hill, 2006.

[7] Xu Yan. Drug Packaging Design based on patients' Psychological needs [J]. Packaging engineering, 2008, 29(8): 139—141.

[8] Han Rong. Packaging Image [M]. Shanghai: Shanghai Sanlian Book Store, 2007. 